Aus der Abteilung Allgemein-, Viszeral- und Kinderchirurgie (Prof. Dr. med. M. Ghadimi) im Zentrum Chirurgie der Medizinischen Fakultät der Universität Göttingen

\title{
Preoperative MELD score as a predictor for post hemihepatectomy complications
}

\author{
INAUGURAL-DISSERTATION \\ zur Erlangung des Doktorgrades \\ der Medizinischen Fakultät der \\ Georg-August-Universität zu Göttingen
}

vorgelegt von

Thamer Hadi Al-Ghamdi

aus

Baljurashi/Saudi Arabien

Göttingen 2013 
Dekan: Prof. Dr.rer.nat.H. K. Kroemer

I. Berichterstatter: PD Dr.med T. Lorf

II. Berichterstatter/in:

III. Berichterstatter/in:

Tag der mündlichen Prüfung: 
Nr. Title

1 INTRODUCTION 1

1.1 Background 1

1.1.1 Basic hepatic anatomy 1

1.1.2 History of hepatic resection 5

$\begin{array}{lll}\text { 1.1.3 Preoperative assessment } & 6\end{array}$

$\begin{array}{lll}\text { 1.1.4 Operative techniques } & 9\end{array}$

$\begin{array}{ll}\text { 1.1.5 Definition of surgical complication } & 11\end{array}$

1.2 Study rationale 12

$\begin{array}{ll}1.3 & \text { Aim of the study } \\ 2\end{array}$

2 PATIENTS AND METHODS 13

2.1 Study design 13

$\begin{array}{lll}2.2 & \text { Source of data } & 13\end{array}$

$\begin{array}{lll}2.3 & \text { Outcome variables } & 14\end{array}$

$\begin{array}{lll}\text { 2.3.1 Classification of surgical complications } & 14\end{array}$

$\begin{array}{ll}\text { 2.3.2 Determination of MELD score } & 16\end{array}$

$\begin{array}{lll}2.4 & \text { Statistical analysis } & 17\end{array}$

3 RESULTS 18

3.1 Prevalence of postoperative complications after hemihepatectomy 18

3.2 Association of preoperative MELD score with post 21 hemihepatectomy complications

3.3 Distribution of patients according to MELD score and incidence of 22 postoperative complication

3.4 Association between preoperative MELD score and grades of 24 postoperative complications after hemihepatectomy procedures

3.5 Association between preoperative AST, INR, creatinine, bilirubin 24 levels and post-hemihepatectomy complications

3.6 The relationship between different factors and development of 26 postoperative complications after hemihepatectomy procedures

3.7 Association between preoperative AST level and postoperative 28 grade of complications after hemihepatectomy procedures

3.8 Association between preoperative creatinine level and postoperative 28 grade of complications after hemihepatectomy procedures 
3.9 Association between bilirubin level and postoperative grade of 29 complications after hemihepatectomy procedures

3.10 Association between INR level and postoperative grade of 30 complications after hemihepatectomy procedures

4 DISCUSSION 32

4.1 Complication rate after hemihepatectomy procedures 32

4.2 The effect of infection on the morbidity and mortality after 33 hemihepatectomy procedures

4.3 Mortality rate after hemihepatectomy procedures

4.4 The predictive indices of MELD score on the morbidity and 35 mortality after hemihepatectomy procedures

4.5 Correlation of extent of liver resection and preoperative aspartate 39 aminotransferase with severity of postoperative complication

4.6 Predictive value of bilirubin on the post-hemihepatectomy 40 complication

4.7 Predictive value of creatinine on the post-hemihepatectomy 41 complication

4.8 Predictive value of INR on the post-hemihepatectomy complication 41

4.9 Correlation of body mass index on the post- hemihepatectomy 42 complications

5 SUMMARY 43

6 REFERENCES

7 APPENDIX $\quad 54$

$\begin{array}{lll}7.1 & \text { List of abbreviations } & 54\end{array}$

$\begin{array}{lll}7.2 & \text { List of tables } & 55\end{array}$

\begin{tabular}{ll}
7.3 & List of Figures \\
\hline
\end{tabular} 


\section{INTRODUCTION}

\subsection{Background}

\subsubsection{Basic hepatic anatomy}

The liver is the largest single organ in the body. It is attached to the diaphragm and the anterior abdominal wall by five ligaments: the falciform, the coronary, two lateral peritoneal folds and the round ligament, a fibrous cord derived from the obliterated umbilical vein. The afferent vessels including hepatic artery and portal vein, and the efferent hepatic bile duct enter through the hepatoduodenal ligament and leave the liver via the porta hepatis (hilum). The liver has a single venous drainage system; the central veins drain into the hepatic veins that drain the liver segmentally and join the inferior vena cava. The liver is also attached to the duodenum by the hepatoduodenal ligament (Snell 1995).

Our anatomical view of the liver structure is influenced by the classification proposed by Couinaud in 1957, which divides the liver into eight functional segments according to its portal vein and hepatic artery supply. Each segment is drained by single bile duct. Hepatic artery, portal vein and bile duct can be found in the center of each segment whereas the hepatic veins branches drain the blood at the periphery of each segment. In general, there are three major hepatic veins. The middle hepatic vein divides the left and right hepatic lobes while the left hepatic 
vein often divides segments 2 and 3 from segment 4 . The middle hepatic vein often unites with the left hepatic vein to form the common trunk before entering the vena cava. The right hepatic vein is the largest hepatic vein and divides the right liver lobe into the anterior and posterior segments. Segment I, formally known as the caudate lobe, is located close to the vena cava. The caudate lobe belongs mainly to left liver lobe, and its small hepatic vein drains directly into the IVC (Figure 1).

A line drawn from the middle of the gallbladder fossa to the IVC roughly divides the liver into left and right lobes and is known as Cantlie's line (Cantlie, 1897). The falciform ligament roughly divides the left lobe into lateral and medial segments; the left hepatic vein usually is located slightly to the left of the falciform ligament (Figure 1).

Understanding liver anatomy is important in liver resection. Resection of a section is called sectionectomy, an anterior right sectionectomy is the removal of segments 5 and 8, and a right posterior sectionectomy is a resection of segments 6 and 7 (Figure 2). Resection of segment 4 can be also called a left medial sectionectomy or simply segmentectomy 4 . Removal of segments 2 and 3 is called left lateral sectionectomy. When the left or the right side of the liver is removed, it is called a left or right hemihepatectomy. Left trisectionectomy or extended left 
hemihepatectomy is the resection of the left hemiliver plus the right anterior section (resection of segments 2-5, 8) (Figure 3). Right trisectionectomy or extended right hemihepatectomy is the resection of the right hemiliver plus the left medial section (Resection of segments 4-8) (Figure 4) (HPB 2000).

With knowledge of the segmental anatomy of the liver, a safe transection plane can be chosen for resection without excessive blood loss and without necrosis of the remaining liver tissue. This specific anatomy of independent functional segments makes it possible to resect parts of the liver without compromising the hepatic function of the remaining segments (Helling and Blondeau, 2005).

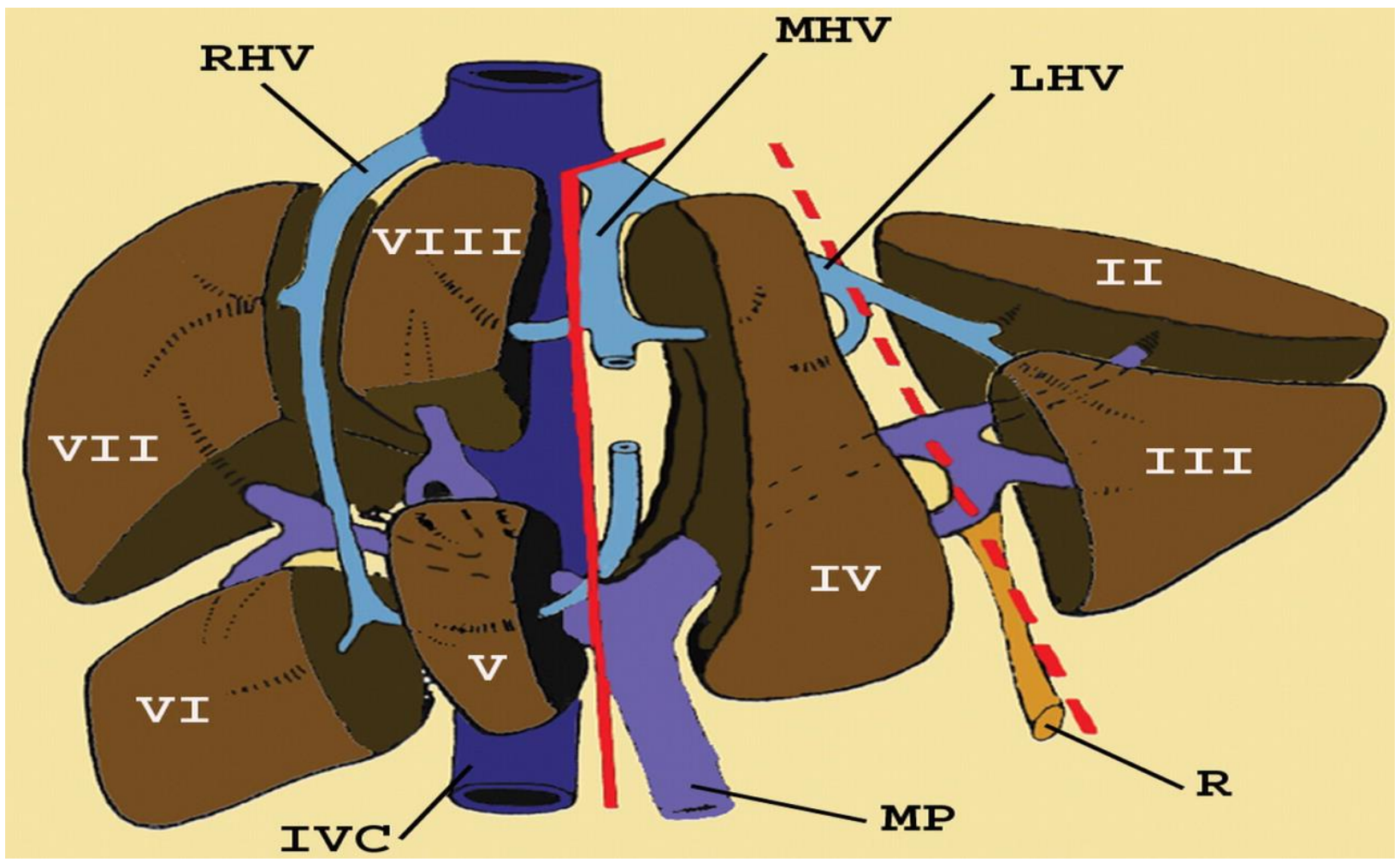

Figure 1: Segmental anatomy of the liver (Soyer et al. 1994) 

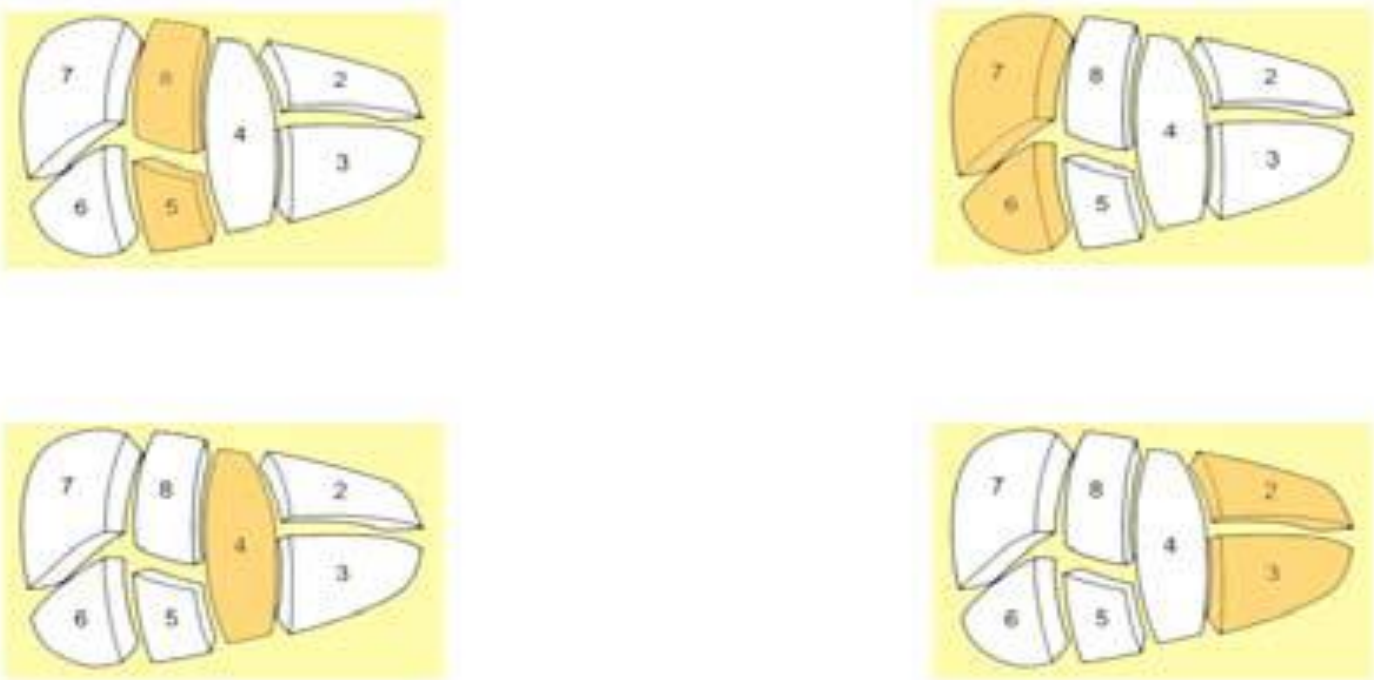

Figure 2. Sectionectomies (Gadžijev 2011)
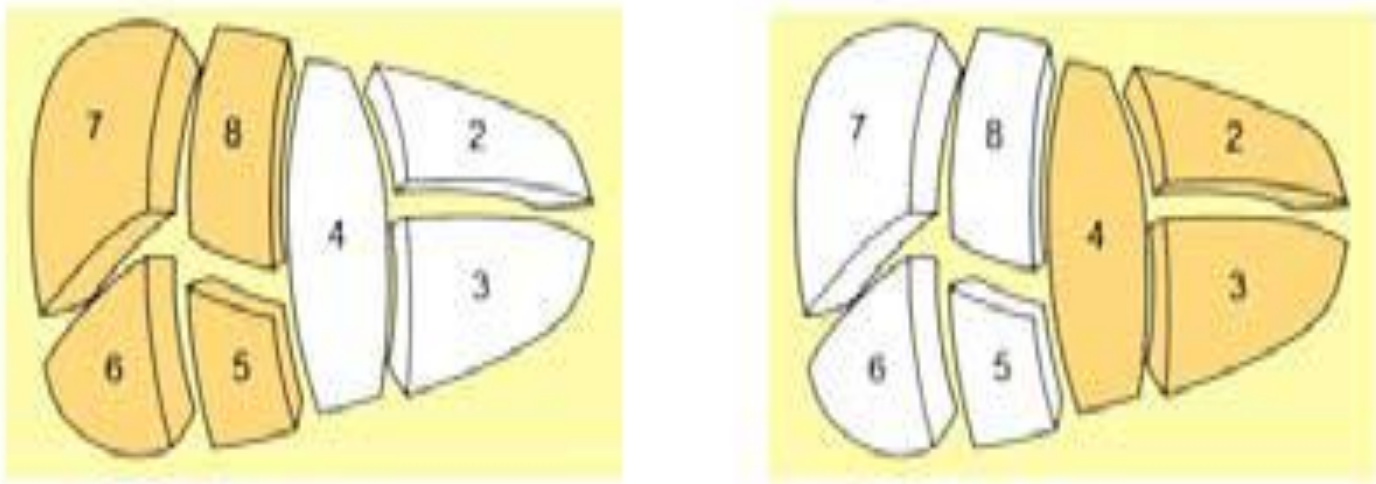

Figure 3: Hemihepatectomies (Gadžijev 2011) 

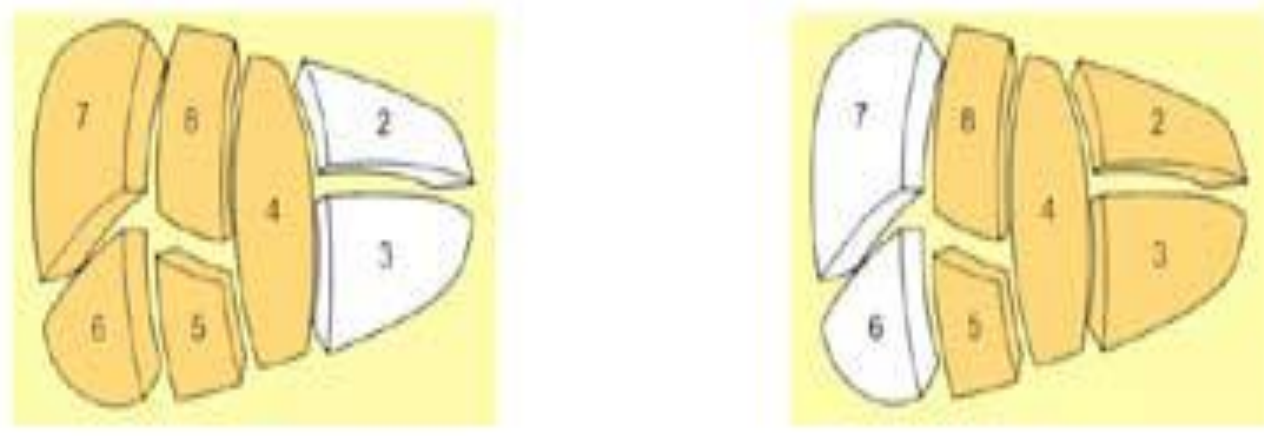

Figure 4: Extended hemihepatectomies or trisectionectomies (Gadžijev 2011)

\subsubsection{History of hepatic Resection}

Important dates in the history of liver resection include the first hepatectomy performed by Lius in 1886 (the patient bleed to death six hours later), the first successful hepatectomy carried out by Langenbuch in 1888 (but which required further laparotomy for bleeding), and the first hemihepatectomy by Wendel in 1911. The principles of liver haemostasis and regeneration were determined in the period 1880-1900. Knowledge of the principles of the inflow and outflow of the liver and vascular control was one of the major advancements. In 1903, Anschütz described the finger fracture technique which was popularized much later by Lin et 
al. in 1960. In 1908, Pringle described compression of the portal triad as a technique to reduce bleeding.

Liver surgery in general has advanced remarkably, but major challenges remain. These include developing more efficient minimally invasive surgical techniques, improving patient selection for any given treatment modality, and eliminating the risk of recurrence, particularly in the liver.

\subsubsection{Preoperative assessment}

In assessing patients with hepatic lesions, remarkable advances have been made in the techniques for evaluating liver disease. In our center, there is no single algorithm that must be followed to arrive at the correct diagnosis. Often, part of the patient's evaluation will have been performed by the referring physician, which may influence the subsequent course of events.

A history of recent symptoms may be revealing and should be elicited. A history of chronic underlying liver disease, chronic hepatitis, heavy alcohol consumption, or blood transfusions is obviously an important component of the overall history. Additionally, certain drugs are associated with the development of hepatic tumors, e.g. anabolic steroids and hepatocellular carcinoma, and oral 
contraceptives and hepatic adenoma, and a thorough history of current and prior medications should be obtained. Pain may be caused by benign or malignant tumors but is usually associated with large lesions, whereas anorexia, weight loss, jaundice, and abdominal distention are more indicative of malignancy. Patients with colorectal cancer may report a history of anemia, a change in bowel habits, or constipation, while patients with metastatic neuroendocrine tumors may have symptoms consistent with hormone overproduction as the initial manifestation of their disease.

A complete physical examination, including a rectal examination and breast and pelvic examinations in women, is important and occasionally yields findings that may help in the diagnosis.

Laboratory investigations such as liver function tests, hepatitis B and C serology, $\alpha$-fetoprotein and carcinoembryonic antigen (CEA) levels can provide valuable information in the initial evaluation of patients.

In the majority of patients, the clinical history, physical examination, and initial screening radiographic studies are insufficient to make the diagnosis, and additional imaging is required to further define the nature of the hepatic lesion. The 
radiological evaluation should define the nature of the hepatic lesion(s), liver parenchyma, and the relationship of the lesion to the major vascular and biliary structures and if clinically indicated, whether the lesion is resectable.

While the unique sensitivity and specificity of a particular imaging technique may provide an accurate diagnosis, multiple studies providing complementary information are sometimes necessary.

Ultrasonography (US) and computed tomography (CT) play an important role in the diagnosis of hepatic lesions and often complement one another. US can provide important diagnostic information for even very small tumors and may be able to give a suggestion as to the dignity of the lesion. Ultrasonography is particularly useful for distinguishing solid from cystic lesions, a distinction that may not be obvious on CT scans, especially with small lesions. While both CT and MRI can be used for staging and screening, a particular advantage of MRI is its ability to show major blood vessels accurately and demonstrate their relationship to tumor masses. Duplex ultrasonography may provide additional information regarding the involvement of major blood vessels and may be particularly useful in the preoperative evaluation of hilar cholangiocarcinoma (Hann et al. 1997). 
Needle biopsy still has a role in some situations, particularly in patients with an apparent malignancy of uncertain origin and in whom resection is contraindicated on clinical grounds or is not possible (Torzilli et al. 1999).

Laparoscopy is increasingly used to allow direct visualization of liver lesions and can be combined with laparoscopic ultrasonography to provide highresolution images (John et al. 1994).

\subsubsection{Operative techniques}

Hepatic resection is the appropriate treatment for a variety of benign and primary or secondary malignant hepatic lesions. In our center, hepatic resection is performed under general anesthesia with a controlled central venous pressure of less than $5 \mathrm{mmHg}$ which minimizes bleeding from disrupted hepatic venous branches. Most intraoperative blood loss results from injury to the hepatic veins and the vena cava. For the majority of hepatic resections in our center, the initial incision should be a right subcostal incision with midline extension or a bilateral subcostal incision with midline extension. The round ligament is transected, leaving a long suture on the hepatic attachment for traction and the falciform ligament is divided up toward the hepatic veins. The lymph nodes in the hilum and retroperitoneum are palpated, and suspicious nodes are sent for frozen-section analysis to exclude extrahepatic dissemination of malignancy. The liver is then 
freed of its diaphragmatic attachments. The right triangular ligament and the coronary ligament are divided with cautery. The liver is carefully palpated, and intraoperative ultrasound is performed to confirm the position of the tumor and its relationship to the hepatic vasculature. The lesser omentum is divided, and the caudate lobe is inspected and palpated. To maintain a good hepatic arterial and portal venous blood supply to the remaining tissue in all major hepatic resection, the afferent vessels to the part of the liver will be resected and hepatic venous outflow should be controlled. This may be done by dissection of the relevant portal pedicle at the hilus and outside the liver substance or alternatively, the major branches may be secured within the liver following division of liver tissue.

The liver parenchyma can be transected in a number of ways, including the finger fracture technique, sharp dissection, and clamp-crush methods (Lin et al 1960 and Lin 1974), in which liver parenchyma is crushed between the thumb and one finger isolating vessels and bile ducts, which can then be ligated and divided. This technique was subsequently improved by using surgical instruments such as small Kelly or Péan clamps (clamp crushing) for blunt transection. 
More recently the cavitron ultrasonic surgical aspirator (CUSA $\left.{ }^{\circledR}\right)$, described by Hodgson in 1979, is used to cut liver parenchyma. The liver parenchyma is transected while the vessels in the parenchyma are skeletonized, allowing their identification before they are damaged. Small vessels $(<2 \mathrm{~mm})$ can be secured by diathermy before division, while larger vessels and branches of the hepatic veins are best secured by ligation or clipping.

The water jet dissector is another new technique for parenchyma transection using the energy of a pressurized water jet with adjustable pressure to separate cells from tissue, differentiating between soft liver parenchyma and blood vessels, thus minimizing blood loss and operation time (Rau 1996).

\subsubsection{Definition of surgical complication}

There are many definitions of the postoperative complication, since the definition of a surgical complication is a challenging task that is still not standardized. The surgical complication is not a fixed reality but depends on the level of surgical skill and the facilities available. Two of the most common and practical definitions, which also correlate with our classifications of complications are by Dindo and Clavien (2008) and Sokol and Wilson (2008). Dindo and Clavien define a complication as "any deviation from the normal postoperative course". 
The definition of Sokol and Wilson is a "surgical complication is any undesirable and unexpected result of an operation affecting the patient".

\subsection{Study rationale}

Although there is a decline in the rate of post-liver surgery complications worldwide, it is still high in some institutions.

Extended hepatic surgery can be performed with low morbidity and mortality in the hands of trained and experienced hepatic surgeons.

\subsection{Aim of the study}

The present study attempts to explore the preoperative and intraoperative predictors of postoperative complications following hemihepatectomy. 


\section{PATIENTS AND METHODS}

\subsection{Study design}

This study includes all patients treated with either right hemihepatectomy, left hemihepatectomy, extended right hemihepatectomy or extended left hemihepatectomy in the University Hospital of Göttingen in the period from 2002 to 2012.

According to the electronic medical records, a total of 443 patients were treated with right or left hemihepatectomy or right or left extended hemihepatectomy. After reviewing and checking all the documents and according to the definitions of the abovementioned operations, they were done only for 267patients. The clinical data was collected for 144 patients where the data was complete as much as possible and examined through a retrospective analysis.

\subsection{Source of data}

The data collected from the electronic medical record system of the University Hospital of Göttingen and the patients' files, including the biometrical data, preoperative studies, intraoperative course of the operations, duration of the operations, operations reports, postoperative laboratory investigations, histology finding and the discharge summary of the patients for the period 2002 to 2012. 


\subsection{Outcome variables}

All the patients undergoing hepatic resection less than standard hemihepatectomy were excluded. The results were either postoperative complications occurring during hospital stay or after discharge, or death of the patient. Death within three months after the operation is the definition of mortality.

\subsubsection{Classification of surgical complications}

A modified classification of surgical complications (Dindo et al. 2004) was used in the current study as shown in Table 1. The definition of a Grade I complication is any deviation from the normal postoperative course without the need for pharmacological treatment or surgical, endoscopic, or radiological interventions. All patients in our study received one or more of the following medications postoperatively as antiemetics, antipyretics, analgesics, diuretics, electrolytes, and physiotherapy which classified according to Dindo classification as Grade I. For this reason, all patients without postoperative complication or any minor deviation which needed the above mentioned medications were classified as Grade I complication. The patients are divided into two groups: patients with Grade II-V complications in whom the postoperative course required pharmacological treatment or surgical, endoscopic, or radiological interventions, and patients without complication represented by Grade I. 
Table 1 illustrates components of the Dindo classification of surgical complications.

\begin{tabular}{|c|c|}
\hline Grade & Definition \\
\hline Grade I & $\begin{array}{l}\text { Any deviation from the normal postoperative course without the } \\
\text { need for pharmacological treatment or surgical, endoscopic, or } \\
\text { radiological interventions. } \\
\text { Allowed therapeutic regimens are: drugs as antiemetics, } \\
\text { antipyretics, analgetics, diuretics, electrolytes, and physiotherapy. } \\
\text { This grade also includes wound infections opened at the bedside. }\end{array}$ \\
\hline Grade II & $\begin{array}{l}\text { Requiring pharmacological treatment with drugs other than such } \\
\text { allowed for grade I complications. } \\
\text { Blood transfusions and total parenteral nutrition are also included. }\end{array}$ \\
\hline $\begin{array}{l}\text { Grade III } \\
\text { Grade IIIa } \\
\text { Grade IIIb }\end{array}$ & $\begin{array}{l}\text { Requiring surgical, endoscopic or radiological intervention. } \\
\text { Intervention not under general anesthesia } \\
\text { Intervention under general anesthesia }\end{array}$ \\
\hline $\begin{array}{l}\text { Grade IV } \\
\text { Grade IVa } \\
\text { Grade IVb }\end{array}$ & $\begin{array}{l}\text { Life-threatening complication (including CNS complications)* } \\
\text { requiring IC/ICU management } \\
\text { Single organ dysfunction (including dialysis) } \\
\text { Multiorgan dysfunction }\end{array}$ \\
\hline Grade V & Death of a patient \\
\hline Suffix “d” & $\begin{array}{l}\text { If the patient suffers from a complication at the time of discharge } \\
\text { (see examples in Table 2), the suffix "d" (for "disability") is added } \\
\text { to the respective grade of complication. This label indicates the } \\
\text { need for a follow-up to fully evaluate the complication. }\end{array}$ \\
\hline
\end{tabular}

Table 1: Classification of Surgical Complications (Dindo et al. 2004, Page 209)

*Brain hemorrhage, ischemic stroke, subarachnoid bleeding, but excluding transient ischemic attacks.

CNS, central nervous system; IC, intermediate care; ICU, intensive care unit. 


\subsubsection{Determination of MELD score}

The Model of End-stage Liver Disease (MELD) is a prospectively developed and validated chronic liver disease severity scoring system that uses serum levels of bilirubin and creatinine, and the international normalized ratio for prothrombin time (INR) to predict survival. In patients with chronic liver disease, an elevated MELD score is associated with increased severity of hepatic dysfunction and increased three-month mortality (Freeman et al. 2002).

The MELD score currently used by the United Network for Organ Sharing (UNOS) for prioritizing allocation of deceased donor organs for liver transplantation is calculated according to the following formula:

MELD = $3.8 \ln *[$ serum bilirubin $(\mathrm{mg} / \mathrm{dL})]+11.2 \ln *[\mathrm{INR}]+9.6 \ln *[$ serum creatinine $(\mathrm{mg} / \mathrm{dL})]+6.4$

The value for serum creatinine used should be 4.0 if the patient has been dialyzed twice within the previous seven days. Any value less than one is given a value of 1 (i.e. if bilirubin is 0.8 , a value of 1.0 is used) to prevent the occurrence of scores below 0 (the natural logarithm of 1 is 0 , and any value below 1 would yield a negative result). All patients with liver cancer will be assigned a MELD score based on how advanced the cancer is. This modification of MELD score calculation was done by UNSO in 2009. 
In cases when only a prothrombin time was reported, the international normalized ratio was calculated in the manner described by van den Besselaar (1996) according to the following equation:

$$
\left[\mathrm{INR}=\left(\mathrm{PT}_{\text {patient plasma }} / \mathrm{PT}_{\text {normal plasma }}\right) \exp \mathrm{ISI}\right]
$$

\subsection{Statistical analysis}

Data were analyzed using SPSS software, version 19. A bivariate analysis was used to identify the correlation of pre-operative variables with the postoperative complication. The chi-square test was used to evaluate categorical variables, and continuous variables were assessed using Student's t-test or MannWhitney test (non-normally distributed variables) for comparison of two groups and a one-way analysis of variance (ANOVA) test for comparison of more than two groups or Kruskal-Wallis test (non-normally distributed variables). A cut-off MELD score of 9 was utilized in the analysis. The validity of grouping the patients with MELD scores greater or less than 9 was demonstrated by Suman et al. (2004) and Farnsworth et al. (2004). A p-value less than 0.05 was considered statistically significant. 


\section{RESULTS}

\subsection{Prevalence of postoperative complications after hemihepatectomy}

A total of 144 patients were treated with either right hemihepatectomy, left hemihepatectomy, extended right hemihepatectomy or extended left hemihepatectomy during the study period (2002-2012).

The age of the patients ranged from 24 to 86 years. The male-to-female ratio was 1.2: 1 . Seventy-five of the 144 patients (52.1\%) developed Grade II to Grade V postoperative complications as shown in Figure 5.

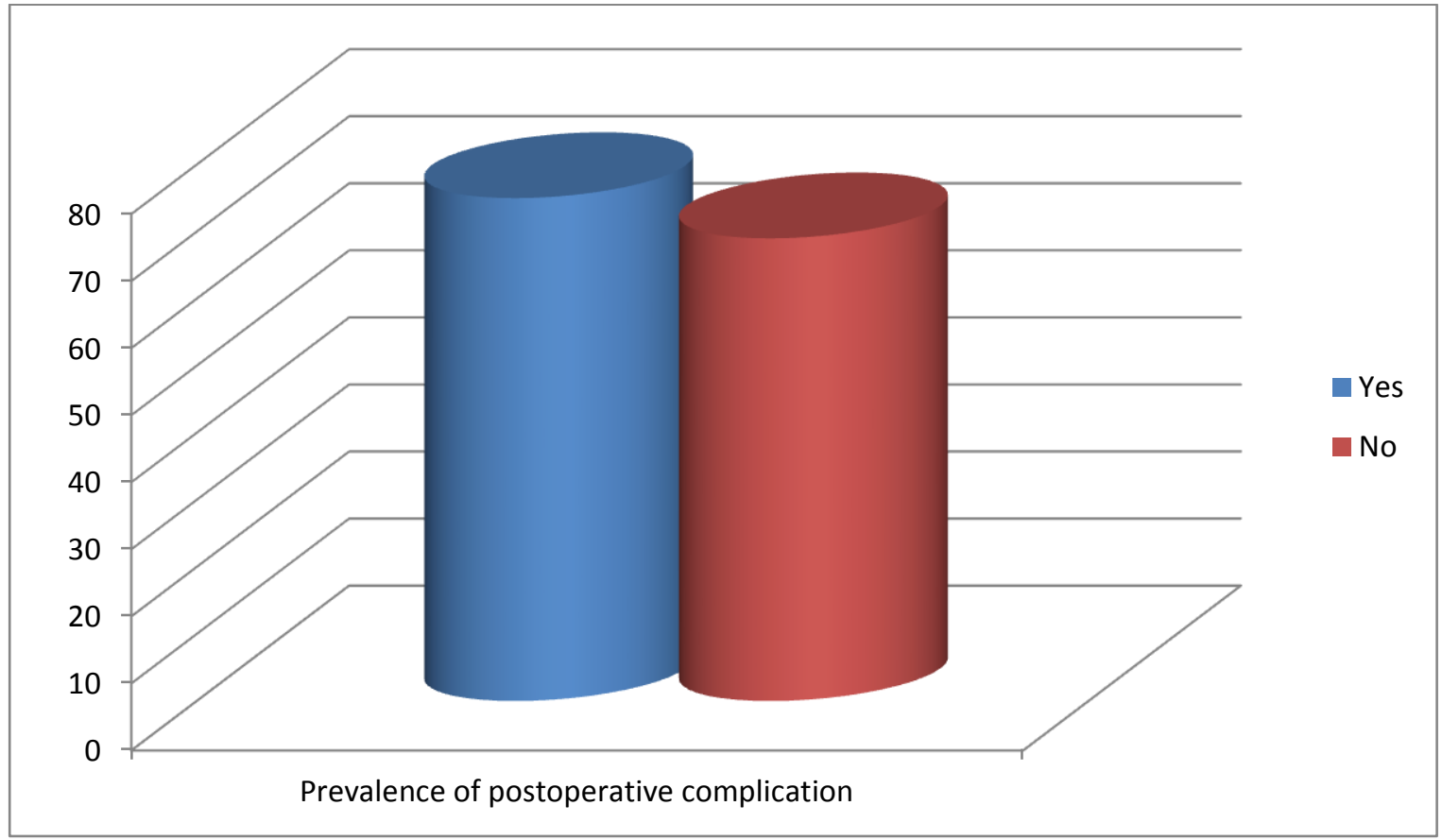

Figure 5: Number of patients with postoperative complications after hemihepatectomy.

The most common complication grade in this study was III-A which was reported in $17.4 \%$ of the patients, followed by Grades II and III- B reported in 
$13.9 \%$ and $11.8 \%$ of the patients, respectively. Sixty-nine patients $(47.9 \%)$ were without postoperative complications and did not require pharmacological treatment or surgical, endoscopic, or radiological interventions (Grade I) patients as illustrated in Figure 6.

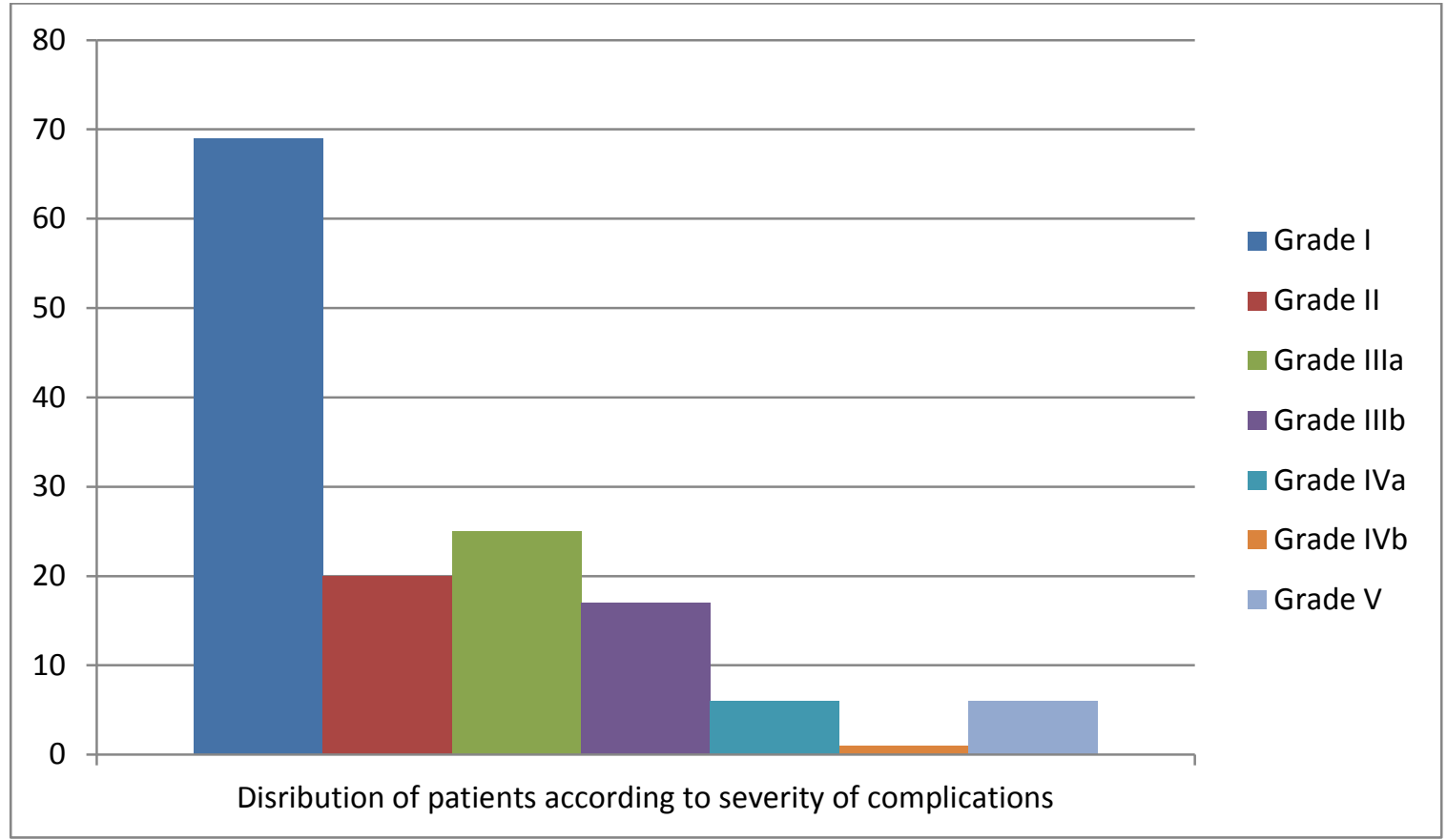

Figure 6: Distribution of patients according to severity grade of postoperative complications.

The most frequent complications were pleural effusion (26.7\%), bile leak (21.3\%), wound dehiscence (13.3\%), ascites and intraabdominal abscess (6.7\%). Death was reported in six cases (8\%).

The intraabdominal complications reported in 59 patients and the pulmonary complications reported in 30 patients indicate that two kinds of complication can 
occur in the same patient. Table 2 summarizes postoperative complications according to their sites and incidence percentage of each complication.

\begin{tabular}{|c|c|c|}
\hline Complications & Number & Percentage \\
\hline \multicolumn{3}{|l|}{ Intra-abdominal } \\
\hline Bile leak & 16 & 21.3 \\
\hline Peritonitis & 4 & 5.3 \\
\hline Subhepatic seroma & 4 & 5.3 \\
\hline Biliodigestive anastomosis leak & 2 & 2.7 \\
\hline Persisting elevated liver enzymes & 4 & 5.3 \\
\hline Ascites & 5 & 6.7 \\
\hline Small intestinal leakage & 2 & 2.7 \\
\hline Colon perforation & 2 & 2.7 \\
\hline Colon inflammation & 1 & 1.3 \\
\hline Cholangitis & 2 & 2.7 \\
\hline Acute pancreatitis & 2 & 2.7 \\
\hline Paralytic ileus & 2 & 2.7 \\
\hline Intraabdominal abscess & 5 & 6.7 \\
\hline Intrahepatic abscess & 1 & 1.3 \\
\hline Gastric ulcer bleeding & 1 & 1.3 \\
\hline Acute duodenal bleeding & 1 & 1.3 \\
\hline Enterocutaneous fistula & 1 & 1.3 \\
\hline Postoperative bleeding & 3 & 4.0 \\
\hline chylous fistula & 1 & 1.3 \\
\hline \multicolumn{3}{|l|}{ Pulmonary } \\
\hline Pleural effusion & 20 & 26.7 \\
\hline Pneumothorax & 1 & 1.3 \\
\hline Respiratory insufficiency & 4 & 5.3 \\
\hline Hoarseness & 1 & 1.3 \\
\hline Pericardial effusion & 1 & 1.3 \\
\hline Atelectasis & 2 & 2.7 \\
\hline Pneumonia & 1 & 1.3 \\
\hline \multicolumn{3}{|l|}{ Miscellaneous } \\
\hline Wound dehiscence & 10 & 13.3 \\
\hline Fascia dehiscence & 3 & 4.0 \\
\hline
\end{tabular}




\begin{tabular}{|l|l|l|}
\hline Minimal wound infection & $\mathbf{1}$ & $\mathbf{1 . 3}$ \\
Acute renal failure & $\mathbf{4}$ & $\mathbf{5 . 3}$ \\
Coagulation disorder & $\mathbf{4}$ & 5.3 \\
Urinary tract infection & $\mathbf{5}$ & $\mathbf{6 . 7}$ \\
Post operative reactive psychosis & $\mathbf{5}$ & $\mathbf{6 . 7}$ \\
Depression & $\mathbf{1}$ & $\mathbf{1 . 3}$ \\
Post operative anemia & 2 & 2.7 \\
Thyrotoxic crisis & $\mathbf{1}$ & $\mathbf{1 . 3}$ \\
Sacral decubitus ulcer & $\mathbf{1}$ & $\mathbf{1 . 3}$ \\
DIC & 2 & 2.7 \\
Death & $\mathbf{6}$ & $\mathbf{8 . 0}$ \\
\hline
\end{tabular}

Table 2: Post hemihepatectomy complications $(\mathrm{n}=75)$

\subsection{Association of preoperative MELD scores with post hemihepatectomy complications}

Postoperative complications occurred in $84.2 \%$ of patients with preoperative MELD scores between 10 and 18 compared to $46.8 \%$ of those with preoperative MELD scores equal to or lower than 9. There was a statistically significant association between the preoperative MELD score and the development of posthemihepatetomy complication $(\mathrm{p}=0.002)$ as illustrated in Table 3.

\begin{tabular}{|l|l|l|l|l|}
\hline \multirow{2}{*}{$\begin{array}{l}\text { Preoperative MELD } \\
\text { Score }\end{array}$} & \multicolumn{2}{|l|}{ Complications } & \multirow{2}{*}{-value } & p-value \\
\cline { 2 - 5 } & $\begin{array}{l}\text { Yes } \\
\text { n. (\%) }\end{array}$ & $\begin{array}{l}\text { No } \\
\text { n. (\%) }\end{array}$ & \\
\hline$\leq 9(\mathrm{n}=124)$ & $58(46.8)$ & $66(53.2)$ & & \\
$10-18(\mathrm{n}=19)$ & $16(84.2)$ & $3(15.8)$ & $\mathbf{9 . 2 5}$ & $\mathbf{0 . 0 0 2}$ \\
\hline
\end{tabular}

Table 3: Association of preoperative MELD score with post hemihepatectomy complications ( $\mathrm{n}=143$; one case is missing) 


\subsection{Distribution of patients according to MELD score and incidence of postoperative complications}

Of a total of 143 patients (one missing), 79 patients had a MELD score of 6. Forty of these developed postoperative complications. Twenty-seven patients had a MELD score of 7, of whom 12 had postoperative complication. Three of the eight patients with a MELD score of 8 developed postoperative complications, while three of the ten patients with a MELD score 9 developed post- operative complication.

A total of 19 patients had a MELD score of 9 or higher. Sixteen of them developed a postoperative complication. Five of six patients with MELD score 10, one of two patients with a MELD score 12, three of four patients with a MELD score 13, one patient with MELD score 14, three patients with MELD score 16, and one patient with MELD score 17 developed postoperative complication as shown in Figures 7 and 8. 


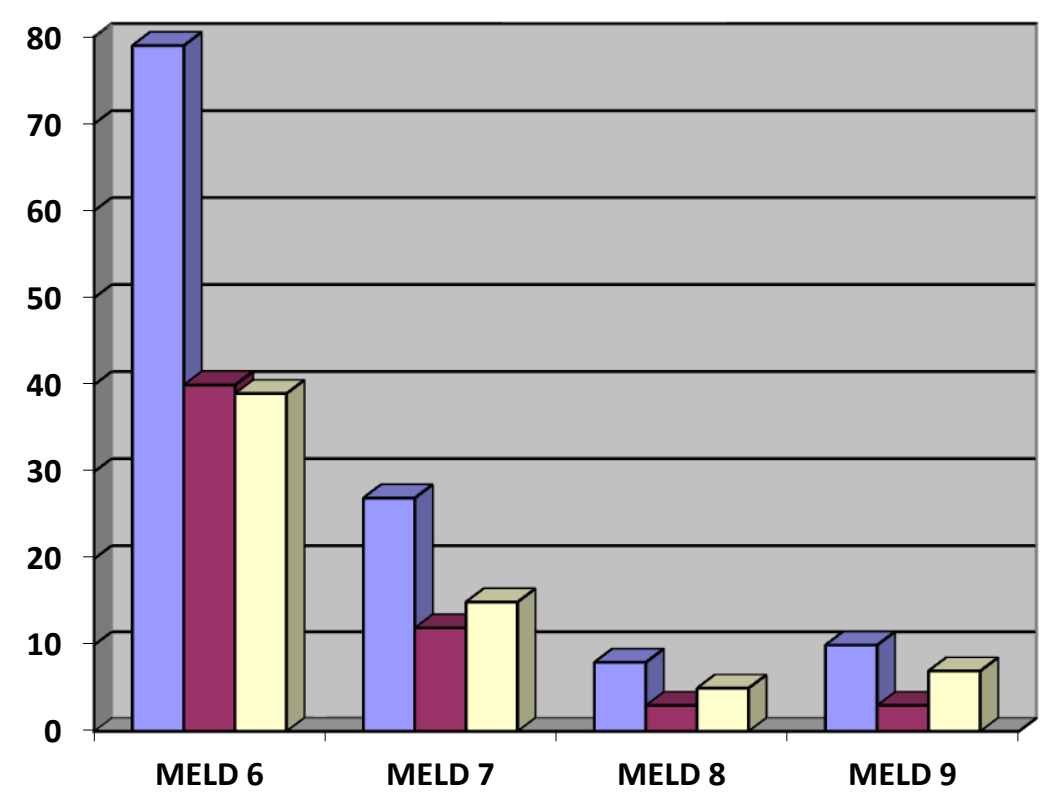

\section{$\square$ Total number \\ $\square$ Patients with complication}

$\square$ Patients without complication

Figure 7: Distribution of patients according to MELD score (6-9) and incidence of postoperative complication

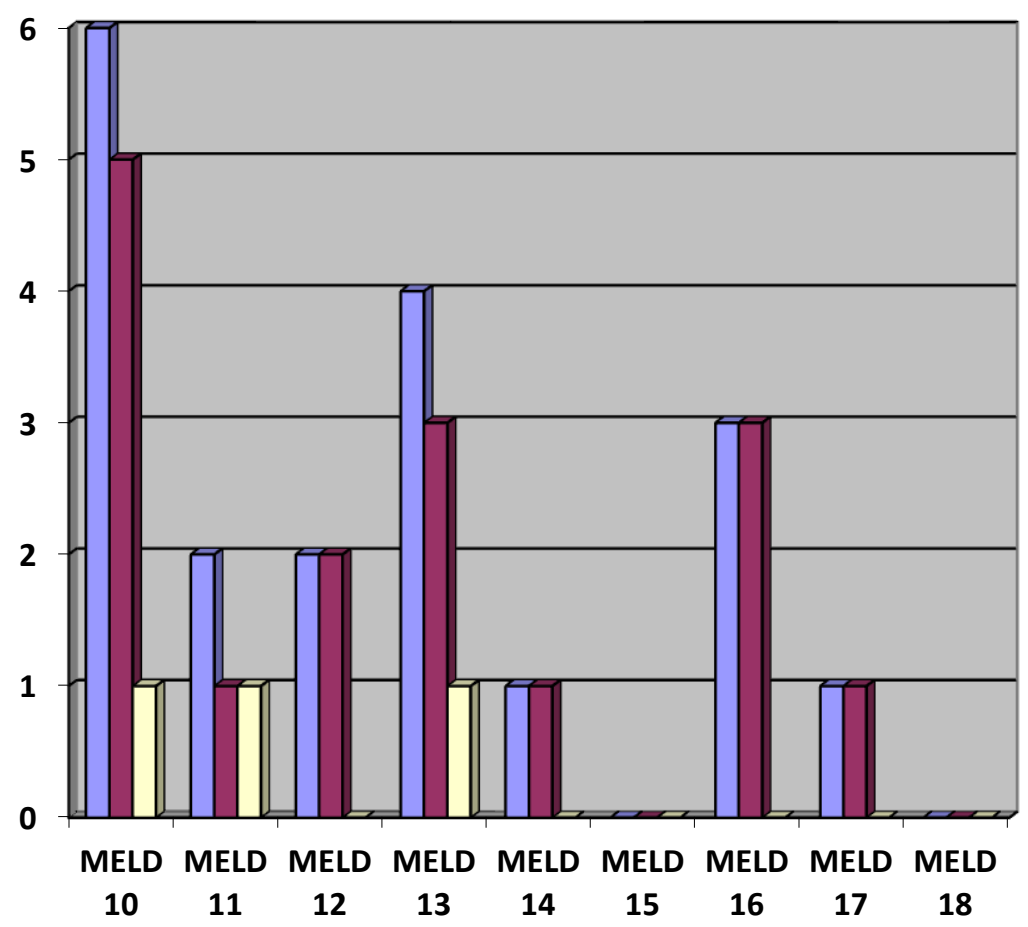

$\square$ Total number $\square$ Patients with complication

$\square$ Patients without complication

Figure 8: Distribution of patients according to MELD score (10-18) and incidence of postoperative complication 


\subsection{Association between preoperative MELD score and grades of postoperative complications after hemihepatectomy procedures}

The association between the preoperative MELD score and the postoperative severity of complication approached statistical significance $(p=0.057$, KruskalWallis); the MELD scores were higher in the patients with postoperative complications Grades V and III-B than in patients with other grades.

\begin{tabular}{|l|l|l|l|l|}
\hline MELD & & Mean (SD) & F-value & p-value \\
\hline Preoperative & Grade 1 (n=71) & $7.0(1.4)$ & & \\
& Grade 2 (n=18) & $7.6(2.9)$ & & \\
Grade 3-a (n=24) & $7.3(2.4)$ & & \\
Grade 3-b (n=17) & $8.6(3.6)$ & & \\
& Grades 4 (n=7) & $7.3(2.2)$ & & \\
& Grade 5 (n=6) & $9.2(4.3)$ & 2.20 & \\
\hline
\end{tabular}

* Kruskal-Wallis test

Table 4: Association between preoperative MELD score and grades of postoperative complications after hemihepatectomy operations

\subsection{Association between preoperative AST, INR, creatinine, and bilirubin levels and post hemihepatectomy complications}

The serum levels of AST, bilirubin, and creatinine were assessed in the patients with postoperative complications and compared to the corresponding 
values of these parameters in patients without complications. The Mann-Whitney test was used because the data were not normally distributed. No statistically significant association was found between the serum levels of AST, creatinine or bilirubin levels and the incidence of post-hemihepatectomy complications (Table $5)$.

The values of INR were normally distributed and the association was tested using Student` t-test. No significant association was found between preoperative INR and the development of postoperative complications as shown in Table 5.

\begin{tabular}{|l|l|l|l|}
\hline \multirow{2}{*}{ Variables } & \multicolumn{2}{|l|}{$\begin{array}{l}\text { Post-hemihepatectomy } \\
\text { complications }\end{array}$} & \multirow{2}{*}{ p-value } \\
\cline { 2 - 3 } & $\begin{array}{l}\text { Yes } \\
\text { mean } \pm \text { SD }\end{array}$ & $\begin{array}{l}\text { No } \\
\text { mean } \pm \text { SD }\end{array}$ & \\
\hline AST (IU/L) & $58.9 \pm 75.5$ & $42.9 \pm 44.2$ & $0.354^{*}$ \\
\hline Bilirubin (mg/dL) & $1.3 \pm 2.5$ & $0.6 \pm 0.4$ & $0.184^{*}$ \\
\hline Creatinine (mg/dL) & $0.9 \pm 0.3$ & $0.8 \pm 0.2$ & $0.581^{*}$ \\
\hline INR & $0.99 \pm 0.13$ & $0.98 \pm 0.1$ & $0.755^{* *}$ \\
\hline
\end{tabular}

* Mann-Whitney test

** Student` t-test

Table 5: Association between preoperative AST, INR, creatinine, and bilirubin levels and post hemihepatectomy complications 


\subsection{The relationship between various factors and the development of postoperative complications after hemihepatectomy procedures}

A bivariate analysis was used to identify the correlation of pre-operative variables including: preoperative diagnosis (malignant, non malignant and LDLT) patient's gender, age (stratified as $<50,51-60,>60$ ), body mass index (stratified as underweight, normal, overweight, and obesity), and the duration of the operation with the occurrence of postoperative complication.

It is evident that exactly half of non-malignant cases (50\%) and more than half of malignant cases (53.2\%) compared to none of LDLT cases had postoperative complications after liver resection as shown in Table 6. However, this difference was not statistically significant, $\mathrm{p}=0.323$. More than half $(60 \%)$ of the patients in the age group 51-60 years and slightly more than half of those over 60 years of age (52.5\%) compared to only $40 \%$ of the patients under the age of 50 had post hemihepatectomy complications, $\mathrm{p}=0.405$. Complication rates did not differ significantly between the BMI groups $(\mathrm{p}=0.220)$. Gender and duration of the operation were also not significantly associated with the development of postoperative complications. 


\begin{tabular}{|c|c|c|c|}
\hline & \multicolumn{2}{|c|}{ Complications } & \multirow[t]{2}{*}{ p-value } \\
\hline & $\begin{array}{l}\text { Yes } \\
\text { n (\%) }\end{array}$ & $\begin{array}{l}\text { No } \\
\text { n (\%) }\end{array}$ & \\
\hline $\begin{array}{l}\text { Group } \\
\text { Malignant }(n=126) \\
\text { Non-malignant }(n=16) \\
\text { LDLT }(n=2)\end{array}$ & $\begin{array}{l}67(53.2) \\
8(50.0) \\
0(0.0)\end{array}$ & $\begin{array}{l}59(46.8) \\
8(50.0) \\
2(100.0)\end{array}$ & 0.323 \\
\hline $\begin{array}{l}\text { Gender } \\
\text { Female }(n=69) \\
\text { Male }(n=75)\end{array}$ & $\begin{array}{l}41(59.4) \\
34(45.3) \\
\end{array}$ & $\begin{array}{l}28(40.6) \\
41(54.7) \\
\end{array}$ & 0.064 \\
\hline $\begin{array}{l}\text { Age in years } \\
\leq 50(n=20) \\
51-60(n=25) \\
>60(n=99)\end{array}$ & $\begin{array}{l}8(40.0) \\
15(60.0) \\
52(52.5) \\
\end{array}$ & $\begin{array}{l}12(60.0) \\
10(40.0) \\
47(47.5) \\
\end{array}$ & 0.405 \\
\hline $\begin{array}{l}\text { Body mass index } \\
\text { Underweight }(n=4) \\
\text { Normal }(n=61) \\
\text { Overweight }(n=46) \\
\text { Obese }(n=20)\end{array}$ & $\begin{array}{l}3(75.0) \\
33(54.1) \\
19(41.3) \\
13(65.0)\end{array}$ & $\begin{array}{l}1(25.0) \\
28(45.9) \\
27(58.7) \\
7(35.0)\end{array}$ & 0.220 \\
\hline $\begin{array}{l}\text { Incision-to-suture time } \\
(\mathbf{m i n}) \\
25-200(\mathrm{n}=42) \\
201-300(\mathrm{n}=41) \\
>300(\mathrm{n}=30)\end{array}$ & $\begin{array}{l}21(50.0) \\
21(51.2) \\
17(43.3)\end{array}$ & $\begin{array}{l}21(50.0) \\
20(48.8) \\
17(56.7)\end{array}$ & 0.787 \\
\hline
\end{tabular}

* Bivariate analysis

Table 6: The relationship between various factors and development of postoperative complications after hemihepatectomy operations: bivariate analysis. 


\subsection{Association between preoperative AST levels and postoperative grade of complications after hemihepatectomy procedures}

As mentioned above, preoperative AST levels were not associated with the incidence of postoperative complications nor with the grade of complications, $\mathrm{p}=0.130$ as shown in Table 7.

\begin{tabular}{|l|l|l|l|}
\hline AST & & Mean (SD) & p-value* \\
\hline Preoperative & Grade 1 (n=68) & $42.5(43.7)$ & \\
& Grade 2 (n=17) & $43.3(38.0)$ & \\
& Grade 3-a (n=24) & $79.0(118.9)$ & \\
& Grade 3-b (n=15) & $57.3(38.5)$ & \\
& Grades 4 (n=7) & $54.1(38.0)$ & \\
& Grade 5 (n=6) & $43.2(26.0)$ & 0.130 \\
\hline
\end{tabular}

* Kruskal-Wallis test

Table 7: Association between preoperative AST level and postoperative grade of complications after hemihepatectomy

3.8 Association between preoperative serum creatinine levels and postoperative complication grade after hemihepatectomy procedures

There was no statistically significant correlation between preoperative serum creatinine levels and the grade of postoperative complications after hemihepatectomy as shown in Table $8(\mathrm{p}=0.138)$. 


\begin{tabular}{|l|l|l|l|l|}
\hline Creatinine & & Mean (SD) & F-value & p-value \\
\hline Preoperative & Grade 1 (n=71) & $0.84(0.22)$ & & \\
& Grade 2 (n=18) & $0.88(0.33)$ & & \\
Grade 3-a (n=24) & $0.82(0.18)$ & & \\
& Grade 3-b (n=17) & $0.89(0.26)$ & & \\
& Grades 4 (n=7) & $0.94(0.25)$ & & \\
& Grade 5 (n=6) & $1.15(0.73)$ & 1.702 & 0.138 \\
\hline
\end{tabular}

* Kruskal-Wallis test

Table 8: Association between preoperative serum creatinine levels and postoperative complication severity after hemihepatectomy procedures

3.9 Association between bilirubin levels and postoperative complication grade after hemihepatectomy procedures

As shown in Table 5 the preoperative bilirubin levels were not associated with the development of post-hemihepatectomy complications. They were also not associated with the severity of the postoperative complications as seen in Table 9.

\begin{tabular}{|l|l|l|l|}
\hline Bilirubin & & Mean (SD) & p-value* \\
\hline Preoperative & Grade 1 (n=71) & $0.64(0.37)$ & \\
& Grade 2 (n=18) & $1.26(2.57)$ & \\
& Grade 3-a (n=24) & $0.95(1.28)$ & \\
& Grade 3-b (n=17) & $1.89(4.03)$ & \\
& Grade 4 (n=7) & $0.97(1.08)$ & \\
\hline
\end{tabular}


* Kruskal-Wallis test

\section{\begin{tabular}{l|l|l} 
Grade $5(\mathbf{n}=\mathbf{6})$ & $1.55(2.10)$ & 0.648
\end{tabular}}

Table 9: Association between preoperative bilirubin levels and postoperative complication grade after hemihepatectomy procedures

\subsection{Association between preoperative INR levels and postoperative} complication grade after hemihepatectomy procedures

Table 10 shows that the preoperative international normalized ratio level is a poor predictor of the postoperative severity of complications.

\begin{tabular}{|c|c|c|c|c|}
\hline INR & & Mean (SD) & F-value & $p$-value \\
\hline Preoperative & $\begin{array}{l}\text { Grade } 1(n=71) \\
\text { Grade } 2(n=18) \\
\text { Grade } 3-a(n=24) \\
\text { Grade } 3-b(n=17) \\
\text { Grade } 4(n=7) \\
\text { Grade } 5(n=6)\end{array}$ & $\begin{array}{l}0.99(0.1) \\
0.98(0.06) \\
1.02(0.17) \\
1.01(0.18) \\
0.91(0.04) \\
0.93(0.06)\end{array}$ & 1.456 & 0.208 \\
\hline
\end{tabular}

* Kruskal-Wallis test

Table 10: Association between preoperative INR levels and postoperative grade of complications after hemihepatectomy procedures

There were three patients with microscopic hepatic cirrhosis, of whom two had no postoperative complications (Grade I). One had a Grade III-A postoperative 
complication. There was also one patient with macroscopic hepatic cirrhosis who had no postoperative complication (Grade I). The MELD scores of these four patients ranged between 6 and 10 preoperatively.

Six patients died giving a mortality rate of $4.17 \%$. The preoperative MELD scores of those patients were not associated with the mortality rate as will be discussed below. 


\section{Discussion}

\subsection{Complication rate after hemihepatectomy procedures}

Intensive evaluation of the patients before liver resection surgery is very important to avoid any abnormal deviation of the postoperative course.

Liver surgery is the collective term for a large variety of operations on the liver for various disorders both benign and malignant. The most common operation performed on the liver is a resection, i.e. removal of part of the liver. Liver resection can be a small piece or a large portion such as a hemihepatectomy or extended hemihepatectomy as performed on the patients in this study. The most typical indication for liver resection is a malignant tumor (Gupta 2012).

Although the complication rates following liver resection have declined over the years, they remain high; $52.1 \%$ of the patients in the current study had at least one complication that required pharmacological treatment or surgical, endoscopic, or radiological interventions. In the National Surgical Quality Improvement Program-Patient Safety Study (NSQIP PSS) sample, $22.6 \%$ of the patients experienced at least one complication and 5.2\% underwent a second operation for complications (Virani et al. 2007). There is a marked diversity in both the reported rates and definitions of complications in the literature. Complication rates in large 
studies of unselected patients range from 22\% to 45\% (Belghiti et al. 2000, Dimick et al. 2003, Jarnagin et al. 2002, Poon et al. 2004, Sun et al. 2005 und Wei et al. 2003). Furthermore, definitions for complications are not standardized, and varying criteria for complication make it difficult to compare the results of different studies. In addition, all patients in the present study underwent hemihepatectomy and extended hemihepatectomy which are the most extensive procedures done on the liver. Also, results of single-center studies may not be reliable indicators of population-wide results, as single-center studies are more sensitive to the institution-specific case mix.

\subsection{The effect of infection on the morbidity and mortality after hemihepatectomy procedures}

Infection after hepatic resection is a major contributor to postoperative morbidity and mortality and might be predictive of long-term outcomes (Neal et al. 2011). Risk factors predictive of postoperative infectious complications are obesity, preoperative biliary drainage, extent of hepatic resection, intraoperative blood loss , co-morbid conditions and postoperative bile leak (Kaibori et al. 2011,Okabayashi et al. 2009, Ferrero et al. 2009 and Garwood et al. 2004). 
In the current study, there were many cases of postoperative infection. Two patients had cholangitis, five patients had an intraabdominal abscess, one patient had intrahepatic abscess. Two patients had atelectasis and one patient had pneumonia. The other instances of infections in this study were wound infections in 11 patients and urinary tract infection in five patients.

The predictive value of various preoperative factors and postoperative complications including infections were studied in our survey. We can confirm that preoperative predictive factors of postoperative infection in earlier studies such as obesity, operative blood loss or postoperative bile leak were not predictive factors of postoperative mortality in our study, as two patients who died had an intraabdominal abscess while the rest of the patients who died did not have any infection in their postoperative course. A bile leak was reported in only one of the six patients who died. The other risk factors, obesity and intraoperative blood loss did not correlate with postoperative morbidity or mortality as will be discussed below.

\subsection{Mortality rate after hemihepatectomy procedures}

Belgithit et al. (2000) studied 747 hepatectomies to evaluate the risk of liver resection. The authors found no intraoperative deaths and an overall mortality rate of $4.4 \%$. In our study the mortality rate was $4.17 \%$. This is somewhat less than that 
in the previous studies and other mortality rates based on population-wide data in unselected patients. For example, based on data from the Nationwide Inpatient Sample (NIS), Dimick et al. reported that the mortality rate for liver resection declined from $10.4 \%$ in the period 1988 - 1999 to 5.3\% in 1998 to 2000 (Dimick et al. 2004). A mortality rate of $2.6 \%$ was reported in the NSQIP PSS study (17). High volume hospitals ( $>10$ resections per year) in the NIS data set reported a 3.9\% overall mortality rate in 1998 to 2000. Although there are important differences between the NSQIP, the NIS and our study data sets (e.g. the present study reported the 3-month mortality rate, while the NSQIP study reported 30-day mortality and NIS reported in-hospital mortality) it must be noted that the outcome after hepatic resection has significantly improved over the past few decades (Belghiti et al. 2000, Jarnagin et al. 2002, Melendez 1998 and Ryan et al. 1982).

\subsection{The predictive values of the MELD score on the morbidity and mortality after hemihepatectomy procedures}

While the Child-Turcotte-Pugh scores and the American Society of Anesthesiology (ASA) physical status classification are predictive of mortality but not morbidity for patients after hepatic resection, the MELD score had no predictive value (Schroeder et al. 2006).

Nagorney and Kamath reported in 2006 that further investigation is necessary before using the MELD score in a clinical setting as a prognostic tool for 
patients other than those awaiting liver transplantation. In addition, they disputed the conclusion that MELD should not be used in the setting of elective hepatic resection. The contradiction between our results and the aforementioned results could be attributed to the fact that in our study we included the preoperative MELD score as a predictive indicator of morbidity but not mortality for patients after hemihepatectomy or extended hemihepatectomy.

The Model for End-stage Liver Disease (MELD) score can accurately predict both postoperative liver failure and postoperative morbidity of cirrhotic patients after hepatectomy for hepatocellular carcinoma. A MELD score equal to or greater than 11 prior to surgery is associated with a very high incidence of liver failure (37.5\%) and postoperative complications (83.3\%) (Cucchetti et al. 2006).

In comparison with our study, the MELD score was also a predictor of postoperative morbidity; the incidence of complications was increased in the patient group with MELD scores equal to or greater than 10; sixteen of 19 patients developed postoperative complications. Note that none of the patients in our study had liver cirrhosis, except for four patients, three of whom had microscopic liver cirrhosis which was only diagnosed by postoperative histology. 
The applicability of MELD in patients without cirrhosis, regardless of the intervention, is unknown. Serum creatinine and INR affect the MELD score (essential components in the MELD score calculation). For this reason, patients with chronic renal failure and using anticoagulants should be excluded before using the MELD score in non-cirrhotic patients (Nagorney and Kamath 2006).

On the other hand, Teh et al. (2005) have shown that a MELD score $\geq 9$ is strongly predictive of perioperative mortality in patients with chronic liver disease who are undergoing hepatic resection. Others have shown that MELD is predictive of perioperative mortality after other operations in patients with cirrhosis (Suman et al. 2004, Befeler et al. 2005, Northup et al. 2005).

We did not concentrate on the cirrhotic patients. It was our aim to see the significance of the MELD score for predicting complications even in non-cirrhotic patients undergoing major hepatic operations. In this study, the preoperative MELD score was significantly associated with post hemihepatectomy complications after adjusting for confounders. It confirmed that there was no association between serum bilirubin, serum creatinine and INR and post hemihepatectomy complications. In addition, chronic renal failure was not present in any patient in our study. We cannot exclude the use of anticoagulants in every patients included in our study because a definitive anticoagulant history was not 
recorded for some patients. However, all INR values were in the normal range except in two patients with INR values 1.4 and 1.6. The patient with INR 1.4 did not develop a postoperative complication but the other patient with INR 1.6 developed a Grade III-A complication.

In our study, there were only four patients with hepatic cirrhosis (one macroscopic and three microscopic which were diagnosed postoperatively). Two of the patients with microscopic cirrhosis had no postoperative complications (Grade I) while one patient had Grade III-A complication. The patient with macroscopic cirrhosis had a Grade I postoperative complication. Their MELD scores were ranged between 6 and 10 preoperatively.

Six patients in this study died giving a mortality rate of $4.17 \%$. The preoperative MELD scores were not significantly associated with their deaths, since four of the patients had MELD scores below 9, while two had MELD scores of 13 and 16, respectively. 


\subsection{Correlation of extent of liver resection and preoperative serum aspartate aminotransferase (AST) levels with severity of postoperative complications}

Four preoperative parameters were identified by Breitenstein et al. (2010) as independent predictors of postoperative complication severity in non-cirrhotic patients undergoing liver resection. These were the American Society of Anesthesiologists (ASA) category, serum transaminase levels (aspartate aminotransferase), extent of liver resection ( $>3$ vs $<3$ segments), and the need for an additional hepaticojejunostomy or colon resection. In their study, the authors described severe complications as complications of Grades III, IV, and mortality (Grade V) (Dindo-Clavien classification).

Grades III to V complications occurred in 159 (26\%) of the 615 patients after liver resection, 90 (15\%) were Grade III, 48 (8\%) were Grade IV, and 21 (3\%) were Grade V.

In the present study, Grade III to Grade V complications occurred in 54 (37.5\%) of the 144 patients after hemihepatectomy or extended hemihepatectomy ( $\geq 4$ segments resection) which corresponds to the patients with severe complication in the previous study, 41 (28.5\%) were grade IIIa and IIIb, 7 (4.9\%) grade IVa and b, and 6 (4.17\%) grade V. 
One of the preoperative predictive factors in the abovementioned study was the resection of more than 3 segments. All of the patients in our study underwent hemihepatectomy or extended hemihepatectomy which is the resection of four or more segments. Preoperative serum AST levels were a second predictive factor. This was not significantly associated with post-hemihepatectomy complications or severity of complication in our study.

\subsection{Predictive value of serum bilirubin for post-hemihepatectomy complications}

As discussed above, the preoperative MELD score is a predictor of posthemihepatectomy complications, and, as is well-known, the MELD score depends on three parameters, one of which is bilirubin. Sitzmann and Greene (Sitzmann and Greene 1994) reported that preoperative hepatic function as assessed by serum bilirubin levels was a potent predictor of postoperative complications. In the present survey, bilirubin was not a predictor of post hemihepatectomy complications, which increases the importance of the MELD score for predicting the development of postoperative complications. 


\subsection{Predictive value of serum creatinine for post-hemihepatectomy complications}

The predictive value of preoperative serum creatinine levels for postoperative complications after liver resection was studied in 2009 by Armstrong et al. The authors divided the patients into two groups: serum creatinine $\leq 124$ $\mu \mathrm{mol} / 1$ (Group 1) and $\geq 125 \mu \mathrm{mol} / 1$ (Group 2). They concluded that there was no difference in the rate of surgical complications between the two groups, but that systemic complications were higher in the group with serum creatinine $\geq 125$ $\mu \mathrm{mol} / \mathrm{l}$.

In our study, serum creatinine was not significantly associated either with the incidence or the severity of post hemihepatectomy complications. In the present study, serum creatinine was also not associated with mortality; five of the six patients who died had normal preoperative creatinine levels while only one patient had $2.6 \mathrm{mg} / \mathrm{dl}$. This result can most probably be attributed to the relatively small sample size in our study.

\subsection{Predictive values of INR for post-hemihepatectomy complications}

A preoperative INR value $>1.2$ was independently associated with a prolonged hospital stay of more than 10 days after liver resection (Greco 2006). 
The INR value is one of the factors that contributes to raise the value of the MELD score, and, as mentioned above, the preoperative MELD score was significantly associated with post hemihepatectomy complications. We found no correlation between INR values and postoperative complications. Depending on this result, INR value is not only or usually the cause of MELD score elevation which make the MELD score a significant predictor of postoperative complication.

\subsection{Correlation of body mass index and posthemihepatectomy complications}

Body mass index was evaluated by Thomas et al. (1997) as a correlate of postoperative complications. In their study in 2,964 patients they found no difference in the complications rates in the four BMI groups (underweight $<20$, normal 20 to 29, overweight 30 to 34 , obese > 34).

In our study, the patients were also divided into four groups: underweight, normal, overweight, and obese. The body mass index did not correlate significantly with the development of postoperative complications which confirms the results of the previous study. 


\section{SUMMARY}

Background: As diagnostic techniques and surgical outcomes improve, the rate that hemihepatectomy is performed for various indications will continue to rise.

Objectives: To explore the preoperative predictors of postoperative complications following hemihepatectomy.

Subjects and Methods: This study is a retrospective analysis of the clinical data of patients who underwent either liver hemihepatectomy or extended hemihepatectomy at the Georg August University Hospital Göttingen during the period 2002 to 2012. The outcomes were either postoperative complications or death of the patient within three months following the operation. A modified classification of surgical complications was used. Preoperative MELD scores, serum AST, creatinine, and bilirubin levels, INR, biometric patient characteristics and intraoperative blood loss were analyzed as predictive factors for post hemihepatectmy complications.

Results: 144 patients underwent hemiheptectomy or extended hemihepatectomy dudring the study period. Postoperative complications were reported in 75 patients (52.1\%). The most frequent complications were pleural effusion (26.7\%), bile leak (21.3\%), wound dehiscence (13.3\%), ascites and intra-abdominal abscess (6.7\%). Six of the patients with complications died ( $8 \%$ of patients with complications). 
Four patients had hepatic cirrhosis (one macroscopic and three microscopic). Two of the patients with microscopic cirrhosis had no postoperative complications (Grade 1), and one developed a Grade III-A complication. The patient with macroscopic cirrhosis had a Grade I complication. Their MELD scores were ranged between 6 and 10 preoperatively. The overall mortality rate was 6 of 144 (4.17\%). The preoperative Meld score was the only significant predictor of postoperative complications.

Conclusions: The complication rate following hemihepatectomy remains high; $52.1 \%$ of the patients in the current study had at least one complication. The overall mortality rate was $4.17 \%$. A high preoperative MELD score is the only significant predictor of the development of post-hemihepatectomy complications. 


\section{REFERENCES}

- Anschütz W. (1903): Über die resektion der Leber. Klin-Vortr. Chir; 14: 356-357.

- Armstrong TH. , Welsh F., Wells J., Chandrakumaran K., John T., and Rees M. ( 2009): The impact of pre-operative serum creatinine on short-term outcomes after liver resection.HPB (Oxford); 11: 622-628.

- Befeler AS, Palmer DE, Hoffman M, Longo W, Solomon H, Di Bisceglie AM. (2005): The safety of intra-abdominal surgery in patients with cirrhosis: model for end-stage liver disease score is superior to Child-Turcotte-Paugh classification in predicting outcome. Arch Surg; 140: 650-654.

- Belghiti J, Hiramatsu K, Benoist S, Massault P, Sauvanet A, Farges O. (2000): Seven hundred forty seven hepatectomies in the 1990s: an update to evaluate the actual risk of liver resection. JACS; 191: 38-46.

- Breitenstein S, DeOliveira ML, Raptis DA, Slankamenac K, Kambakamba P, Nerl J, et al.(2010): Novel and simple preoperative score predicting complications after liver resection in noncirrhotic patients. Ann Surg; 252: 726-734.

- Cantlie J. (1897): On a new arrangement of the right and left lobes of the liver. Proceedings - Anatomical Society of Great Britain and Ireland; $\underline{32}$ :49. 
- Couinaud C: Le foie. Etudes anatomique et chirurgicales. Masson, Paris 1957.

- Cucchetti A, Ercolani G,Vivarelli M, Cescon M, Ravaioli M, La Barba G, (2006): Impact of model for end-stage liver disease (MELD) score on prognosis after hepatectomy for hepatocellular carcinoma on cirrhosis. Liver Transpl; 12:966-971.

- Dimick JB, Cowan JA, Knol JA, Upchurch GR (2003): Hepatic resection in the United States: indications, outcomes, and hospital procedural volumes from a nationally representative database. Arch Surg; 138: 185-191.

- Dimick JB, Wainess RM, Cowan JA, Upchurch GR, Jr., Knol JA, Colletti LM. (2004): National trends in the use and outcomes of hepatic resection. JACS; 199: 31-38.

- Dindo D, Clavien PA. (2008): What is a surgical complication? World J Surg; 32: 939-941.

- Dindo D, Demartines N, Clavien P. (2004): Classification of surgical complications; a new proposal with evaluation in a cohort of 6336 patients and results of a survey. Ann Surg; 240: 205-213.

- Farnsworth N, Fagan SP, Berger DH, Awad SS. (2004): Child-TurcottePugh versus MELD score as a predictor of outcome after elective and emergent surgery in cirrhotic patients. Am J Surg; 188: 580-583. 
- Freeman RB, Wiesner RH, Harper A, McDiarmid SV, Lake J, Edwards E, et al. (2002): The new liver allocation system: moving toward evidence-based transplantation policy. Liver Transpl; $\underline{8}:$ 851:858.

- Ferrero A, Lo Tesoriere R, Viganò L, Caggiano L, Sgotto E, Capussotti L. (2009): Preoperative biliary drainage increases infectious complications after hepatectomy for proximal bile duct tumor obstruction. World J Surg; $\underline{33}$ : 318-325.

- Gadžijev EM (2011): Surgical terminology of liver anatomy and liver resection. BH Surgery; 1 : 6-13.

- Garwood RA, Sawyer RG, Thompson L, Adams RB (2004): Infectious complications after hepatic resection. Am Surg; 70: 787-792.

- Greco E, Nanji S, Bromberg IL, Shah S, Wei AC, Moulton CA, et al. (2011): Predictors of peri-opertative morbidity and liver dysfunction after hepatic resection in patients with chronic liver disease. HPB (Oxford); $\underline{13}$ : 559-565.

- Gupta S. (2012): Liver surgery. Health base online.

Available at:http://www.healthbase.com/resources/organ-transplant/livertransplantation/liver-surgery.html. 
- Hann LE, Greatrex K, Bach AM, Fong Y, Blumgart LH. (1997): Cholangiocarcinoma at the hepatic hilus: sonographic findings. AMJ; $\underline{168}$ : 985-989.

- Helling T. and Blondeau B. (2005): Anatomic segmental resection compared to major hepatectomy in the treatment of liver neoplasms. HPB (Oxford); $\underline{7}$ : $222-225$.

- HPB (2000): The terminology committee of the IHPBA. The Brisbane 2000 terminology of hepatic anatomy and resections; 333-339.

- Hodgson WJB (1979): Aufses A Jr. Surgical ultrasonic dissection of liver. Surgical Rounds;2: 68-72.

- Jarnagin WR, Gonen M, Fong Y, DeMatteo RP, Ben-Porat L, Little S, et al. (2002): Improvement in perioperative outcome after hepatic resection: analysis of 1,803 consecutive cases over the past decade. Ann Surg; 236: 397-406.

- John TG, Greig JD, Crosbie JL, Miles WFA, Garden OJ. (1994): Superior staging of liver tumors with laparoscopy and laparoscopic ultrasound. Ann Surg; 220: 711-719.

- Kaibori M, Ishizaki M, Matsui K, Kwon AH. (2011): Postoperative infectious and non-infectious complications after hepatectomy for hepatocellular carcinoma. Hepatogastroenterology; ㅁ:1747-1756. 
- Langenbuch C. (1888): Ein Fall von Resektion eines linksseitigen Schnurlappens der Leber, Heilung. Berl Klin Wochenschr; 25: 37-38.

- Lin TY, Chen KM, Liu TK. (1960): Total right hepatic lobectomy for primary hepatoma. Surgery; $\underline{48}: 1048-1060$.

- Lin TY (1974): A simplified technique for hepatic resection: the crush method; Ann Surg; 180: 285-290.

- Lius A. (1886): Di un adenoma del fegato. Gazzetta delle Cliniche; 23:225-230.

- Melendez JA, Arslan V, Fischer ME, Wuest D, Jarnagin WR, Fong Y et al. (1998): Perioperative outcomes of major hepatic resections under low central venous pressure anesthesia: blood loss, blood transfusion, and the risk of postoperative renal dysfunction. J Am Coll Surg; 187: 620-225.

- Nagorney DM, Kamath PS. (2006): Predictive indices of morbidity and mortality after liver resection. Ann Surg; 244: 373-379.

- Neal CP, Mann CD, Garcea G, Briggs CD, Dennison AR, Berry DP (2011): Preoperative systemic inflammation and infectious complications after resection of colorectal liver metastases. Arch Surg; 146: 471-478.

- Northup PG, Wanamaker PC, Lee VD, Adams RB, Berg CL. (2005): Model for End-stage Liver Disease (MELD) predicts non-transplant surgical mortality in patients with cirrhosis. Ann Surg; 242: 244-251. 
- Okabayashi T, Nishimori I, Yamashita K, Takahashi S, Konishi M, Kinoshita T (2009): Risk factors and predictors for surgical site infection after hepatic resection. J Hosp Infect; $\underline{73}$ : 47-53.

- Poon RT, Fan ST, Lo CM, Liu CL, Lam CM, Yuen WK, et al. (2004): Improving Perioperative Outcome Expands the Role of Hepatectomy in Management of Benign and Malignant Hepatobiliary Diseases. Ann Surg; 240: 698-710.

- Pringle JH (1908): Notes on the Arrest of Hepatic Hemorrhage Due to Trauma. Ann Surg; 48: 541-549.

- Rau HG, Meyer G, Jauch KW, Cohnert TU, Buttler E, Schildberg FW (1996): Liver resection with the water jet: conventional and laparoscopic surgery: Chirurg; 67: 546-551.

- Ryan WH, Hummel BW, McClelland RN. (1982): Reduction in the morbidity and mortality of major hepatic resection. Experience with 52 patients. Am J Surg; 144: 740-743.

- Schroeder RA, Marroquini CE, Phillips Bute B, Khuri S., Henderson WG, Kuo PC. (2006): Predictive indices of morbidity and mortality after liver resection. Ann Surg; 243: 373-379. 
- Sitzmann JV, Greene PS. (1994): Perioperative predictors of morbidity following hepatic resection for neoplasm, A multivariate analysis of a single surgeon: Experience with 105 patients. Ann Surg; 219: 13-17.

- Snell RS: Clinical anatomy for medical student. $6^{\text {th }}$ ed.: Washington DC, 1995.

- Sokol DK, Wilson J. (2008): What is a surgical complication? World J Sur; 12: 9471-9476.

- Soyer P, Breittmayer F, Gad M. (1991): Imagerie tridimensionelle de la segmentation heapique: anatomie et volumetrie. Rev Imag Med; 3: 741-745.

- SoyerP, Bluemke DA, Bliss DF, Woodhouse CE, Fishman EK. (1994): Surgical segmental anatomy of the liver: demonstration with spiral CT during arterial portography and multiplanar reconstruction. AJR Am J Roentgenol; 163: 99-103.

- Suman A, Barnes DS, Zein NN, Levinthal GN, Connor JT, Carey WD. (2004): Predicting outcome after cardiac surgery in patients with cirrhosis: a comparison of child-Pugh and MELD scores. Clin Gastroenterol Hepatol; 2 719-723.

- Sun HC, Qin LX, Wang L, Ye QH, Wu ZQ, Fan J, et al. (2005): Risk factors for postoperative complications after liver resection. Hepatobiliary Pancreat Dis Int; 4: 370-374. 
- Teh SH, Christein J, Donohue J, Que F, Kendrick M, Farnell M. (2005): Hepatic resection of hepatcellular carcinoma in patients with cirrhosis: model for End-stage Liver Disease (MELD score predicts perioperative mortality). J Gastrointest Surg; 9: 1207-1215.

- Thomas EJ, Goldman L, Mangione CM, Marcantonio ER, Cook EF, Ludwig L, et al. (1997): Body mass index as a correlate of postoperative complications and resource utilization.Am J Med; 102: 277-283.

- Torzilli G, Minagawa M, Takayama T, Inoue K, Hui AM, Kubota K,et al.(1999): Accurate preoperative evaluation of liver mass lesions without fine-needle biopsy. Hepatology; 30: 889-893.

- UNOS (28.01.2009). MELD/PELD calculator documentation" (PDF). Retrieved (21.02.2010). Available at: http://www.unos.org/.

- Van den Besselaar AM (1996): Precision and accuracy of the international normalized ratio in oral anticoagulant control. Haemostasis; 26: 248-265.

- Virani S, Michaelson JS, Hutter MM, Lancaster RT, Warshaw AL, Henderson WG, Khuri SF, Tanabe KK. (2007): Morbidity and mortality after liver resection: results of the patient safety in surgery study. J Am Coll Surg; 204:1284-1292. 
- Wei AC, Tung-Ping Poon R, Fan ST, Wong J. (2003): Risk factors for perioperative morbidity and mortality after extended hepatectomy for hepatocellular carcinoma. Br J Surg; 90: 33-41.

- Wendel W. (1911): Beitraege zur chirurgie der leber. Arch Klin Chir; $\underline{95}$ 887-894. 


\section{APPENDIX}

7.1 List of abbreviations

\begin{tabular}{|l|l|}
\hline Abbreviation & Description \\
\hline AFP & Alphafetoprotein \\
\hline AST & Aspartate Transaminase \\
\hline BMI & Body Mass Index \\
\hline CEA & Carcinoembryonic Antigen \\
\hline CI & Confidence Interval \\
\hline CT & Computed Tomography \\
\hline CUSA & Cavitron Ultrasonic Surgical Aspirator \\
\hline GOT & Glutamic Oxaloacetic Transaminase \\
\hline INR & International Normalized Ratio \\
\hline IU/L & International Units per Liter \\
\hline IVC & Inferior Vena Cava \\
\hline LDLT & Living Donor Liver Transplantation \\
\hline LHV & Left Hepatic Vein \\
\hline MELD & The Model of End-Stage Liver Disease \\
\hline mg/dL & milligrams per deciliter \\
\hline MHV & Middle Hepatic Vein \\
\hline MP & Main Portal Vein \\
\hline MRI & Magnetic Resonance Imaging \\
\hline NSQIP PSS & The National Surgical Quality Improvement \\
\hline OR & Odds Ratio \\
\hline PVE & Portal Vein Embolisation \\
\hline R & Round ligament \\
\hline RFDS & The Hydrojet and the Radiofrequency Dissection Sealer \\
\hline RHV & Right Hepatic Vein \\
\hline SPSS & Statistical Package for Social Sciences \\
\hline TIPS & Transjugular Intrahepatic Portosystemic Shunt \\
\hline UNOS & $\begin{array}{l}\text { United Network for Organ Sharing Programme-Patient Safety } \\
\text { Study }\end{array}$ \\
\hline US & Ultrasonography \\
\hline
\end{tabular}


7.2 List of tables

\begin{tabular}{|c|c|c|}
\hline Table No. & Title & Page No. \\
\hline 1 & - Classification of Surgical Complications. & 15 \\
\hline 2 & - Post hemihepatectomy complications $(n=60)$. & 20-21 \\
\hline 3 & $\begin{array}{lcr}\text { - Association between MELD score } & \text { and } \\
\text { postoperative } & \text { Complications } & \text { after } \\
\text { hemihepatectomy Operations. } & & \end{array}$ & 21 \\
\hline 4 & $\begin{array}{l}\text { - Association between preoperative MELD score } \\
\text { and grades of postoperative Complications after } \\
\text { hemihepatectomy Operations. }\end{array}$ & 24 \\
\hline 5 & $\begin{array}{l}\text { - Association between pre-operative AST, INR, } \\
\text { creatinine, levels and post hemihepatectomy } \\
\text { complications. }\end{array}$ & 25 \\
\hline 6 & $\begin{array}{l}\text { - The Relationship between different factors and } \\
\text { development of postoperative Complications after } \\
\text { hemihepatectomy Operations. }\end{array}$ & 27 \\
\hline 7 & $\begin{array}{l}\text { - Association between preoperative AST level and } \\
\text { post-hemihepatectomy complications. }\end{array}$ & 28 \\
\hline 8 & $\begin{array}{l}\text { - Association between preoperative creatinine level } \\
\text { and posthemihepatectomy complications. }\end{array}$ & 29 \\
\hline 9 & $\begin{array}{l}\text { - Association between preoperative bilirubin level } \\
\text { and post-hemihepatectomy complications. }\end{array}$ & 29-30 \\
\hline 10 & $\begin{array}{l}\text { - Association between preoperative INR level and } \\
\text { post-hemihepatectomy complications. }\end{array}$ & 30 \\
\hline
\end{tabular}




\subsection{List of Figures}

\begin{tabular}{|c|c|c|}
\hline $\begin{array}{c}\text { Figure } \\
\text { No. }\end{array}$ & Title & Page No. \\
\hline 1 & - Segmental anatomy of the liver & 3 \\
\hline 2 & - Sectionectomies. & 4 \\
\hline 3 & - Hemihepatectomy & 4 \\
\hline 4 & - Extended hemihepatectomy or Trisectionectomies & 5 \\
\hline 5 & $\begin{array}{l}\text { - Prevalence of postoperative Complications after } \\
\text { Hemihepatectomy. }\end{array}$ & 18 \\
\hline 6 & $\begin{array}{l}\text { - Distribution of patients according to grades of } \\
\text { postoperative Complications. }\end{array}$ & 19 \\
\hline 7 & $\begin{array}{l}\text { - Distribution of patients according to MELD score } \\
\text { (6- 9) and incidence of post- operative complication }\end{array}$ & 23 \\
\hline 8 & $\begin{array}{l}\text { - Distribution of patients according to MELD score } \\
(10-18) \text { and incidence of post- operative } \\
\text { complication }\end{array}$ & 23 \\
\hline
\end{tabular}




\section{ACKNOWLEDGMENTS}

I would like to express my sincere thanks and deepest gratitude to

PD Dr.med T. Lorf for his fruitful directions, useful advice, professional cooperation and endless support during the conduction of this work.

I would like to express my sincere thanks and deepest gratitude to Prof. Moataz M. Abdel-Fattah for his great support during the statistical analysis of this research work.

\section{Thamer Al-Ghamdi}




\section{Lebenslauf:}

Am 17.08.1983 wurde ich in Baljurashi- Saudi Arabien geboren. Ich bin verheiratet und habe zwei Kinder.

Meine Schulbildung absolvierte ich von 1988 bis 2000 in Saudi Arabien. Abgeschlossen habe ich diese Ausbildung mit dem erweiterten Sekundarabschluss.

Das Studium der Humanmedizin begann ich im Sommer 2001 an der KönigKhalid- Universität. Im Juni 2006 absolvierte ich den Bachelorgrad der Humanmedizin. 2007 beendete ich das praktische Jahr im NationalgardeKrankenhaus Jeddah.

Danach arbeitete ich zwei Jahre lang von 01.09.2007 bis 31.08.2009 in der KönigKhalid- Universität auf Allgemeinchirurgie- Abteilung und im Assir- Zentral Krankenhaus als Assistenzarzt.

Septemper 2009 besuchte ich Deutschkurse im Goethe- Institut- Göttingen. Am 28.05.2010 absolvierte ich den B2- Intensivkurs sowie die B2- Prüfung. Seit dem 01.09.2010 bin ich Assistenzarzt in der Allgemein- und Viszeralchirurgie der Georg- August- Universität- Göttingen. Ich habe vom 01.09.2010 bis zum 31.08.2011 auf der Hepatobil- und Transplantationsschirurgie die Aufgaben des Assistenzarztes ausgeübt. Vom 01.09.2011 bis zum 20.03.2012 war ich auf der Allgemein- und Viszeralchirurgischen Station tätig. Vom 01.04.2012 bis 31.10.2012 war ich als Assistenzarzt auf der chirurgischen Intensivstation tätig. Danach war ich vom 01.11.2012 bis zum 31.01.2013 nochmals auf der Allgemeinund Viszeralchirurgie tätig.

Seit dem Wintersemester 2011/12 arbeitete ich an der vorliegenden Dissertation. 